\title{
MANAGEMENT PLAN AND SURVEILLANCE MONITORING FOR AN URBAN LAKE IN A COASTAL TOURISTIC TOWN
}

\author{
MARÍA-TERESA SEBASTIÁ-FRASQUET, JOSÉ-ANDRÉS SANCHIS-BLAY, \\ JUAN TORMO-FLORES, VICENT-JESÚS ALTUR-GRAU \& JESÚS PENA-REGUEIRO \\ Instituto de Investigación para la Gestión Integrada de Zonas Costeras (IGIC). Universitat Politècnica de València. \\ C/ Paranimf, 1. Grau de Gandia 46730 (Valencia, Spain).
}

\begin{abstract}
Urban lakes have been created for different purposes, such as storing rainwater and avoiding flooding of adjacent urban areas. As an added value, they can be important recreational areas with an intrinsic aesthetic value. These artificial systems are characterised by very shallow waters, large amount of nutrient inputs and reduced water flow. These characteristics make them very prone to eutrophication process with the consequent deterioration of water quality and aesthetic value. The objective of this study is to present the management plan for a small urban lake (11,264 $\mathrm{m}^{2}$ and $1.5 \mathrm{~m}$ average depth) in Tavernes de la Valldigna (Valencia, Spain). This urban lake was constructed in a natural depression after the important flooding caused by the Júcar River overflow $\left(15,000 \mathrm{~m}^{3} / \mathrm{s}\right.$ peak flow) and the breaking of the Tous Dam in 1982. It works as storm tank and it has a pumping station to alleviate flow directly to the Mediterranean Sea. Around the lake, there is a recreational area that is mostly used in summer during touristic season. Since its construction it has suffered repeated events of fish deaths and bad odours that cause the alarm of residents and tourists. Municipal authorities worried by the environmental health risk and the economic impact on the tourism industry decided to undertake a restoration project. The results of this study present the initial status diagnosis and the proposed management plan. For guarantying the success of the implemented measures, a surveillance monitoring is designed.

Keywords: biofilters, urban lakes, water quality.
\end{abstract}

\section{INTRODUCTION}

\subsection{Study area}

La Goleta Lake is an urban lake located at Tavernes de la Valldigna town (Eastern Spain) (Fig. 1). This urban lake was constructed in a natural depression after the important flooding caused by the Júcar River overflow $\left(15,000 \mathrm{~m}^{3} / \mathrm{s}\right.$ peak flow) and the breaking of the Tous Dam in 1982. Its current dimensions are $11,264 \mathrm{~m}^{2}$ and $1.5 \mathrm{~m}$ average depth. It works as storm tank, and it has a pumping station to alleviate flow directly to the Mediterranean Sea.

The Mediterranean area (Eastern Spain) is a very important touristic destination, with important population increase during summer. Around the lake, there is a recreational area that is mostly used in summer during touristic season. Since its construction, the lake has suffered repeated events of fish deaths and bad odours that cause the alarm of residents and tourists. 


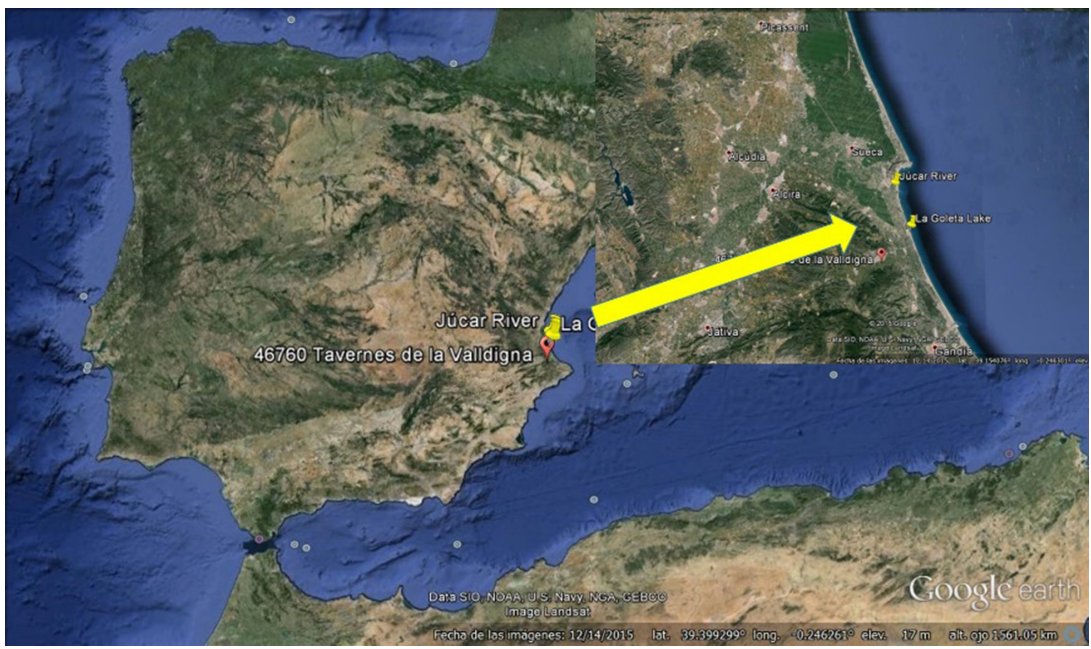

Figure 1: Study area location.

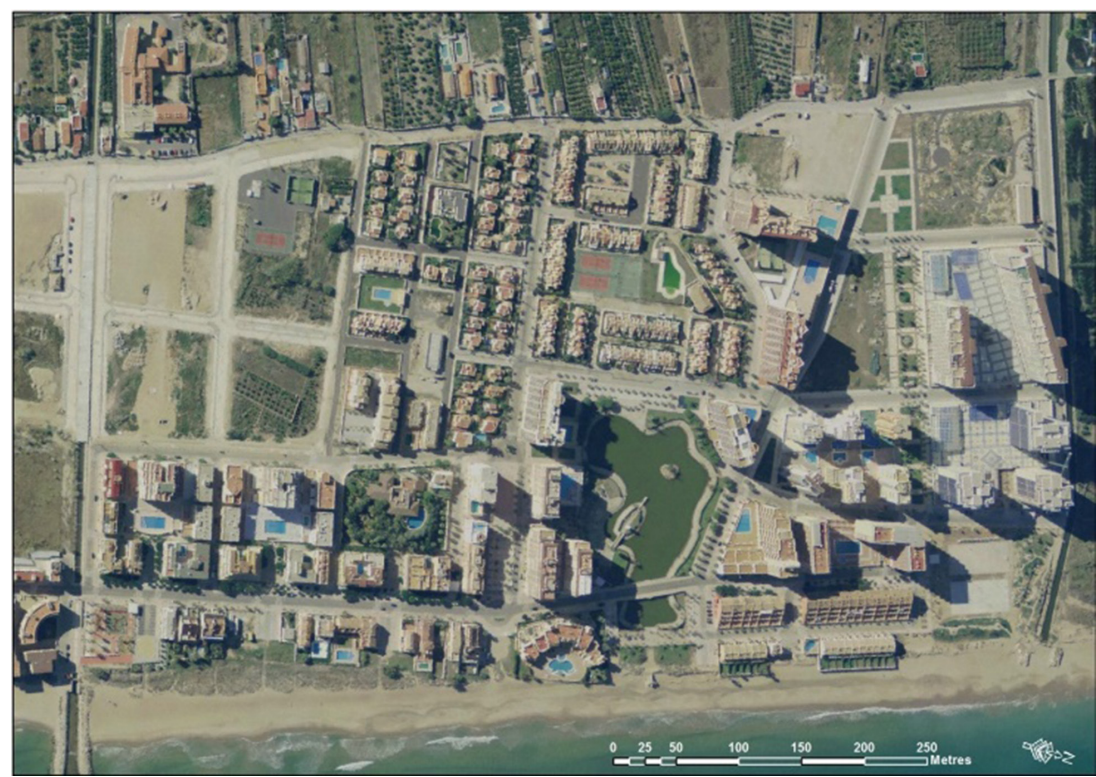

Figure 2: La Goleta Lake aerial photograph.

Municipal authorities worried by the environmental health risk and the economic impact on tourism industry decided to undertake a restoration project. The results of this project are presented here.

\section{METHODOLOGY}

The first step is the initial diagnosis of La Goleta Lake status. Several steps were followed: 1) The Lake drainage basin was delimited with ArcGIS 10 based on altitude and slope 
parameters. 2) Land uses in the study area were classified and quantified to analyse the origin of runoff waters. 3) Water inputs and outputs were identified. 4) Solids inputs were identified and estimated when possible (e.g. total amount of organic matter due to aquatic bird population). 5) Diagnosis sampling was done (February 2015).

The second step is listing objectives to improve the Lake overall quality and analysing the possible restoration measures needed to achieve them. These measures will be prioritised according to sustainability and preventive criteria.

The last step is a proposal of surveillance monitoring to evaluate the success of restoration measures in achieving the improved Lake quality objectives fixed.

In the diagnosis sampling, the following parameters were measured in the water column: conductivity, turbidity and dissolved oxygen vertical profiles with a multiparametric probe, ammonium, nitrites, nitrates, phosphorus, silica, chlorophyll $a$ and photosynthetic pigments. In the sediments, the following parameters were analysed: oxygen demand and \% organic matter. Three sampling points were selected: G1 deeper area, G2 next to the island and G3 shallower area. Water samples were collected in plastic bottles at subsurface $(5 \mathrm{~cm}$ depth) and sediments were collected with a manual dredge.

\section{RESULTS}

\subsection{Initial diagnosis}

La Goleta Lake collects runoff of nearly $200.000 \mathrm{~m}^{2}$ of urban area, the calculated surfaces are included in the Table 1.

Water inputs are direct rain and runoff. It is hypothesised that maybe water inputs from the detrital aquifer, however, vertical profiles did not show any changes in water parameters to confirm that input (additional monitoring is needed to confirm). The main water output is due to evaporation. Only in hard rain events water is pumped to the sea. First flush has been demonstrated as an important source of pollution to receiving waters [1].

Solid inputs are due mainly to aquatic birds, turtles and fishes' excretion, and rests of feeding (bread, fruits, etc.). Excreted uric acid is transformed to $\mathrm{NH}_{3}$ which is toxic for fishes, to avoid toxicity problems $\mathrm{NH}_{3}$ concentration should be lower than $0.05 \mathrm{mg} / \mathrm{L}$ [2]. According to observed aquatic bird population the annual input of organic matter is demonstrated in the Table 2. Calculations have followed the recommendations by [3, 4].

Due to low temperatures 5 to $7^{\circ} \mathrm{C}$ water was well mixed and dissolved oxygen values were above $9 \mathrm{mg} / \mathrm{L}$. The most relevant values were the high oxygen demand 305.6 a $589.1 \mathrm{mg} \mathrm{O}{ }_{2} / \mathrm{m}^{2} \mathrm{~h}$ of sediments that were black coloured and smell bad which is characteristic of anoxic processes. No fauna was observed in the sediments.

Table 1: Surface types in drainage basin.

\begin{tabular}{llc}
\hline Surface type & Area $\left(\mathrm{m}^{2}\right)$ & Percentage $(\%)$ \\
\hline Sidewalks & 41,640 & 22.3 \\
Roads/ pavement & 33,044 & 17.7 \\
Buildings & 39,848 & 21.4 \\
Building lots & 62,627 & 33.6 \\
Green areas & 9,327 & 5.0 \\
\hline
\end{tabular}


Table 2: Organic matter input due to aquatic birds excretion.

\begin{tabular}{lcccc}
\hline Birds & Quantity & $\begin{array}{c}\text { kg/year } \\
\text { organic matter }\end{array}$ & $\mathrm{N} \mathrm{kg}$ /year & $\mathrm{P} \mathrm{kg} /$ year \\
\hline Geese & 20 & 1.825 & 31 & 15 \\
Ducks & 32 & 1.752 & 30 & 14 \\
& Subtotal & $\mathbf{3 . 5 7 7}$ & 61 & 29 \\
\hline
\end{tabular}

\subsection{Restoration measures}

The objectives of restoration measures are summarised in the following figure 3; each objective relates to the others as represented by arrows.

3.2.1 Proposal 1: Pumping water to the sea and refilling the lake with groundwater Objective: recirculating water (Figure 4)

Advantages: needed infrastructure existent, pump already installed (see Figure 4)

Disadvantages: bad groundwater quality, nitrate concentration higher than $50 \mathrm{mg} / \mathrm{L}$. Pumping energetic cost.

\subsubsection{Refilling with surface waters}

Objective: recirculating water

Disadvantages: Bad quality of surface water in the watershed due to nitrates and pesticides from agricultural activity and high organic matter content and other contaminants due to wastewater effluents. High cost of infrastructure.

\subsubsection{Creating a closed circuit for recirculating water}

Objective: recirculating water (Figure 5)

Advantage: effective recirculation will increase aeration and increase water quality, reduced electric power needed.

Disadvantages: energetic cost and infrastructure cost

\subsubsection{Using aerators}

Objective: increasing dissolved oxygen (Figure 6)

Advantages: already installed, the recirculation system will help in mixing oxygenated water

Disadvantages: electric energy cost, need to work together with recirculating system for improved efficiency

\subsubsection{Chemical products with oxygen}

Objective: Increasing dissolved oxygen

Advantages: fast results, products for water column and sediments

Disadvantages: does not act on the cause of the problem, hazardous for the biota, high cost due to lake volume

3.2.6 Lake dredging

Objective: Increasing dissolved oxygen and decreasing nutrients (Figure 7) 


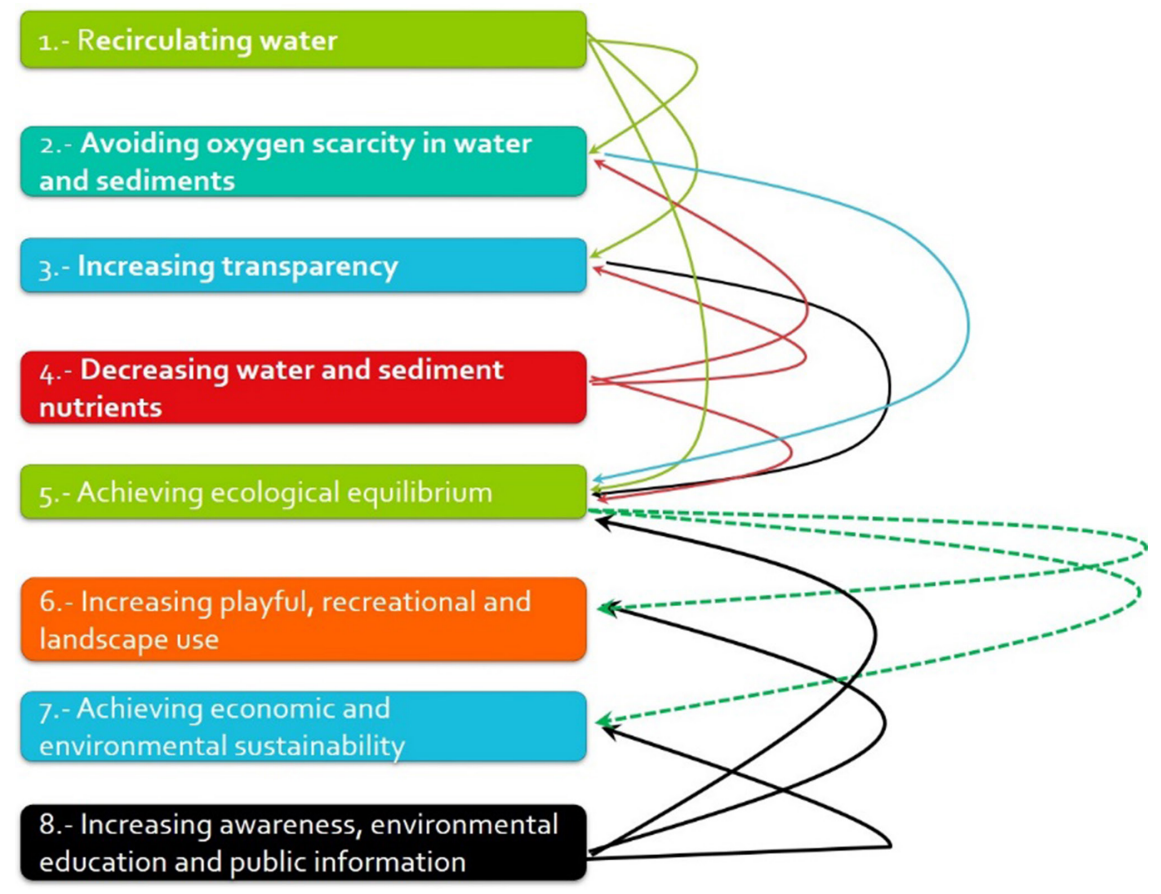

Figure 3: Restoration measures objectives. For achieving these objectives, the following measures are proposed.

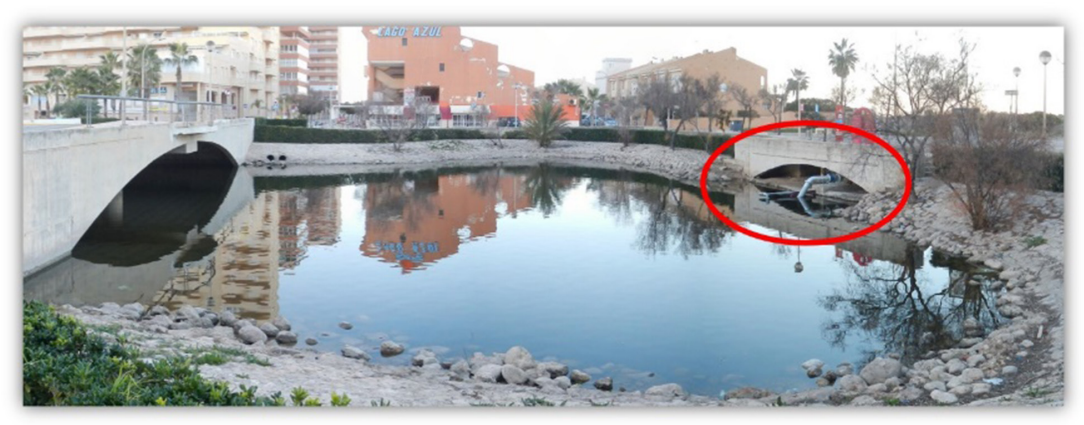

Figure 4: Infrastructure for pumping water towards the sea.

Advantages: removing sediments will decrease the oxygen demand and the pump of nutrients from them

Disadvantages: $3,000-5,000 \mathrm{~m}^{3}$ of sediments means high cost, will eliminate lake biota during dredging, needs other measures to avoid dredging again at mid-term.

3.2.7 Constructive elements (fountains, waterfalls, etc.)

Objective: increasing dissolved oxygen, increasing landscape attractive 


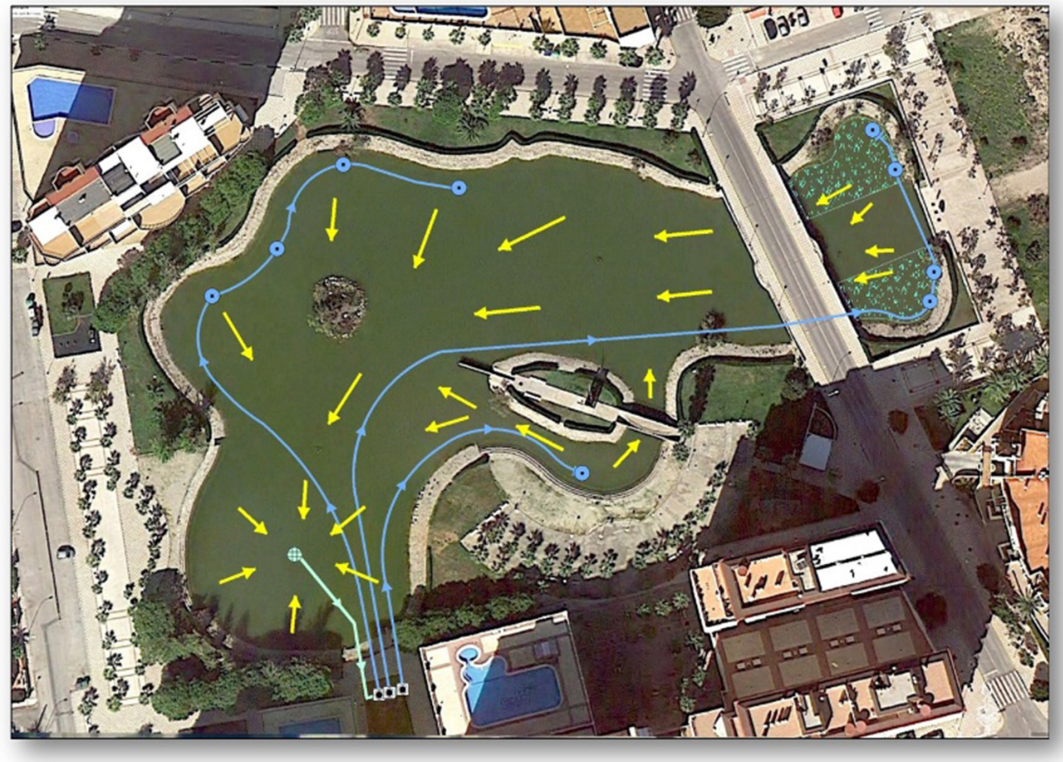

Figure 5: Closed recirculation system.

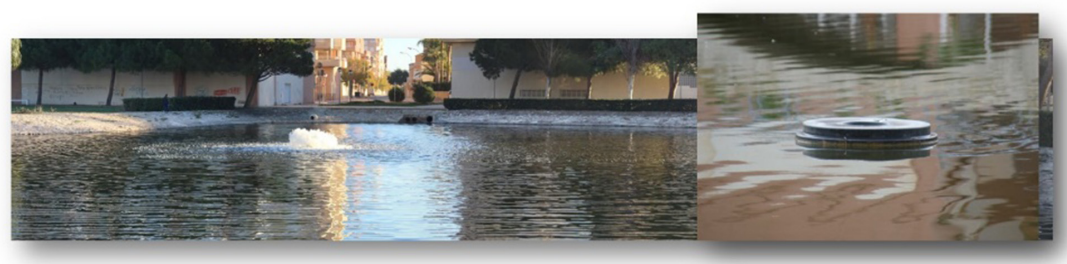

Figure 6: Aerators operating in La Goleta Lake.

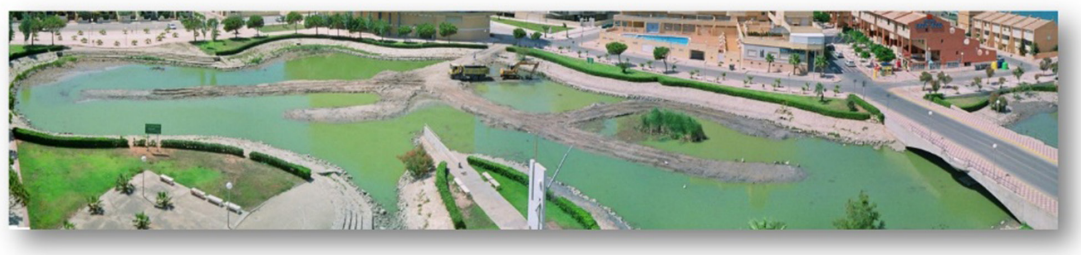

Figure 7: La Goleta Lake being dredged (year 2005).

Advantages: low maintenance cost, increased landscape attractive Disadvantages: high construction cost, vandalism

\subsubsection{Water filtration}

Objective: increasing transparency

Advantage: fast and visible results 
Disadvantages: high construction (machine rooms for pumps and filtration system) and maintenance cost (electric power), need to connect with sewer system.

\subsubsection{Chemical products (algaecide, flocculants)}

Objective: increasing transparency

Advantage: fast and visible results

Disadvantages: does not act on the cause of the problem, hazardous for the biota, high cost due to lake volume.

\subsubsection{Biofilters}

Objective: increasing dissolved oxygen, increasing transparency, decreasing nutrients, ecological equilibrium, increasing landscape value and economic and environmental sustainability (Figure 8).

Advantages: increase dissolved oxygen, reduce nutrients, reduces other contaminants, permanent results, sustainable measure, increase landscape value

Disadvantages: more time needed for results (not immediate results), maintenance is needed

\subsubsection{UV-C clarifiers}

Objective: increasing transparency

Advantages: disinfection system, can be coupled with the recirculating water system, reduced electric power consume

Disadvantages: installation and functioning cost

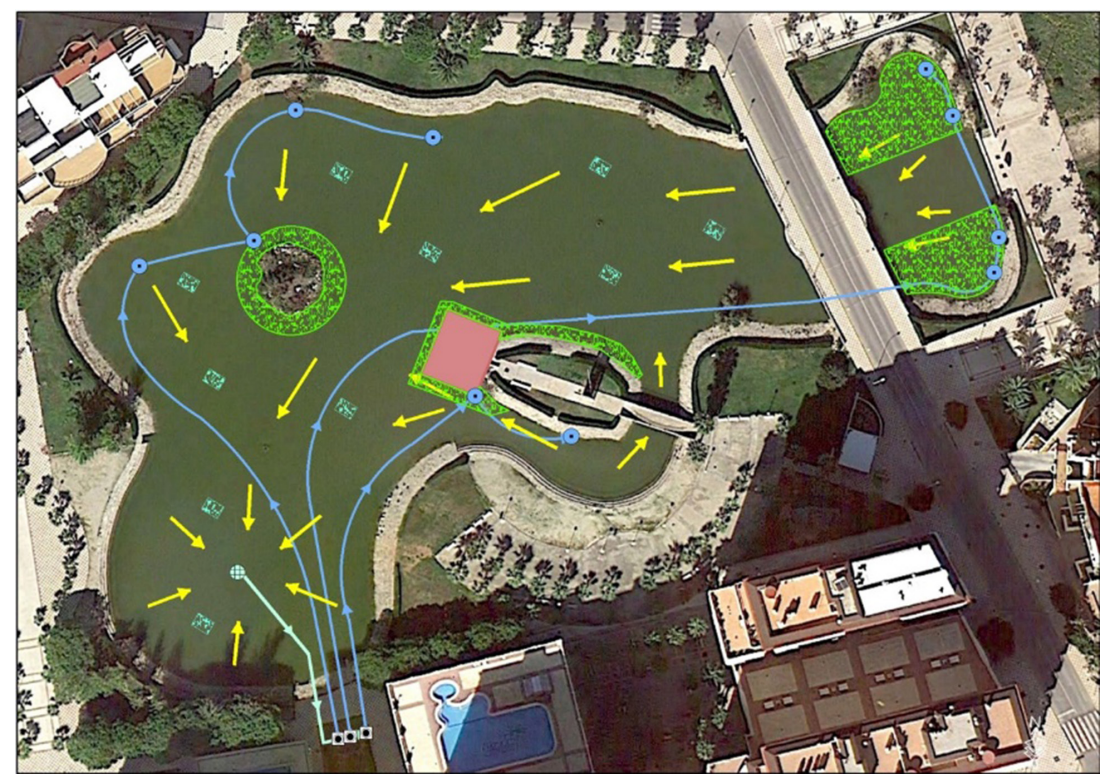

Figure 8: Simulation of biofilters in La Goleta Lake (arrows representing the recirculating water system). 


\subsubsection{Ultrasounds}

Objective: increasing transparency

Advantages: reduces phytoplankton abundance, reduce electric power consume, some dispositive are coupled with water quality sensors.

Disadvantages: medium cost, may be hazardous for some species, not effective with all phytoplankton groups $[5,6]$.

\subsubsection{Filtering system at lake inputs}

Objective: increasing transparency (Figure 9)

Advantages: suspended solids and nutrients reductions

Disadvantages: installation and maintenance cost

\subsubsection{Diverting first flush water}

Objective: increasing water transparency

Advantages: suspended solids, nutrients and other contaminants reductions

Disadvantages: construction costs

\subsubsection{Fauna control measures (ducks, geese, turtles)}

Objective: reducing nutrients inputs (Figure 10)

Advantages: eliminating aquatic birds will reduce an annual average of 3,700 $\mathrm{kg}$ of organic matter. This will increase water transparency, reduce sediment oxygen demand, improve ecological equilibrium and reduce maintenance cost

\subsubsection{Renewable energy (solar panels 'solar tree')}

Objective: economic and environmental sustainability, increasing landscape value

Advantages: reducing operating costs of other measures that need electric power supply (recirculating water, filtration, etc.)

3.2.17 Awareness campaigns, environmental education and public information Objective: increase social awareness

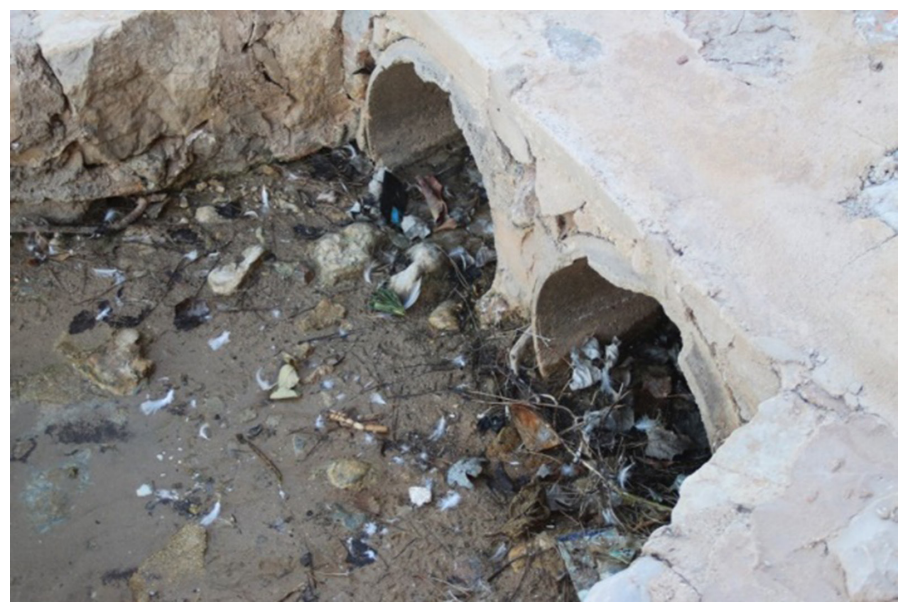

Figure 9: Filtering systems must be installed before water inputs. 


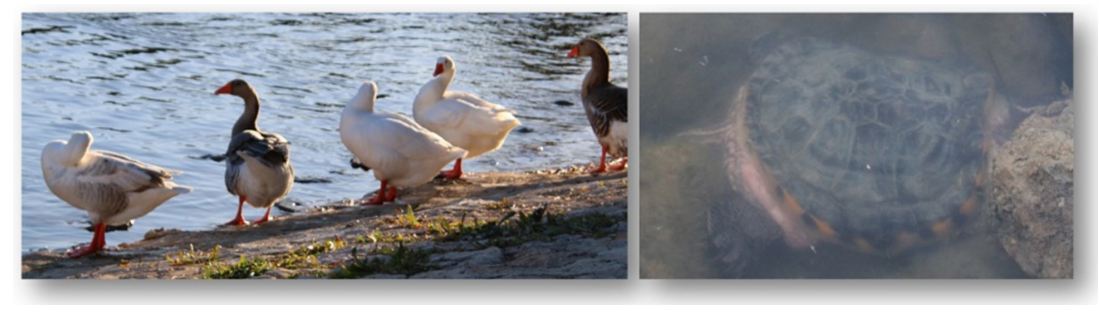

Figure 10: La Goleta Lake fauna.

Advantages: involving local people and tourist in lake ecological status, avoiding reintroduction of invasive species like Florida turtle (Trachemys scripta elegans), avoiding organic matter inputs due to animal feeding.

Among the described restoration measures will be prioritise those accomplishing sustainability criteria and preventing the causes of the eutrophication problem: a recirculating water systems that helps increasing the efficiency of the installed aerators will be installed, biofilters and other constructive elements (fountains, cascades, etc.) will be built and renewable energy will be used for electric power supply of these systems. Additionally, fist flush waters will be diverted to sewer and filtration systems will be installed at water inputs. Aquatic birds control and eradication of invasive species as well as people awareness are also key for reducing nutrient and organic matter inputs.

\subsection{Surveillance monitoring}

A surveillance monitoring is necessary to analyse the effectivity of implemented restoration measures. This monitoring will allow a deeper knowledge of the annual lake cycle, and will serve for applying additional measures if needed or discarding useless ones.

Monitoring will include the following parameters:

\subsubsection{Water quality}

The following variables will be measured: temperature, conductivity, salinity, suspended solids, transparency, turbidity, oxygen, ammonium, nitrites, nitrates, soluble reactive phosphorus and total phosphorus.

Temporal variability in these shallow lakes is very high, so fortnightly samplings are recommended. Spatial variability is very low, so it is recommended to sample three points at subsurface ( $5 \mathrm{~cm}$ depth) in the following fixed points: G1 the deeper lake area, G2 next to the island area and G3 the shallower area. These points will cover the maximum spatial variability.

Additionally, a vertical profile of conductivity will be performed with a CTD probe (Conductivity - Temperature - Depth) to detect saline water intrusion.

This monitoring will allow to analyse nutrient trends in the water column. The nutrient ratio is a key to understand phytoplankton cycle and to know the potentially limiting nutrient for phytoplankton growth. Being able to discriminate the potentially limiting nutrient is essential for more effective measures on the target nutrient. Measuring ammonium concentration is particularly important due to its toxicity for fishes.

\subsubsection{Sediment quality}

The following variables will be measured: $\%$ organic matter, oxygen demand and total phosphorus. 
Temporal variability is lower in the sediments than in the water column, so monthly sampling is recommended. For taking into account spatial variability, samples will be collected at the same points than in the water column: G1, G2 and G3. Samples will be collected with a manual dredge.

\subsubsection{Biota}

The following variables will be measured in the water column: photosynthetic pigments (to determine phytoplankton groups abundance and composition) and toxin producing phytoplankton (microscope samples will be analysed for the detection of species that are toxin producers). The abundance of toxin producers is also particularly important as high toxin levels can also be the cause of fish deaths.

Sampling will be performed the same than for other water variables.

At the sediment samples (monthly collected) will be observed the presence or absence of benthic fauna and its relative abundance. At present conditions, benthic fauna is inexistent, so its appearance will be an alert of improved sediment quality.

Additional measures will be undertaken to supervise the effectivity of control programs for aquatic bird and introduced species such as Florida turtle (Trachemys scripta elegans).

\section{CONCLUSIONS}

It is recommended that after restoration measures are implemented the surveillance monitoring will be continued at least one complete year. After that period, the effectiveness of restoration measures must be evaluated. The need of additional measures should be tackled if necessary. Surveillance sampling frequency could be reduced depending on the observed results.

\section{ACKNOWLEDGMENTS}

The authors would like to thank Ayuntamiento de Tavernes de la Valldigna (Valencia, Spain) for the economic support of the project and their encouragement of research activities.

\section{REFERENCES}

[1] Russo, B., Malgrat Bregolat, P. \& Suñer Roqueta, D., Depósitos para retención de primera escorrentía. criterios de diseño y operación. $v$ Congreso de la Ingeniería Civil Desarrollo y sostenibilidad en el marco de la ingeniería. colegio de ingenieros de caminos, canales y puertos, Sevilla, 26, 27 y 28 de noviembre de 2007, ISBN: 9788438004036 $1^{\text {a }}$ ed., $1^{\text {a }}$ imp. de $02 / 2010$.

[2] Camargo, J.A. \& Alonso, A., Contaminación por nitrógeno inorgánico en los ecosistemas acuáticos: problemes medioambientales, criterios de calidad del agua, e implicaciones del cambio climático. Ecosistemas, 16(2), pp. 98-110, 2007, available at http://www. revistaecosistemas.net/index.php/ecosistemas/issue/view/17 (accessed 19 February 2016).

[3] Williams, C.M., Gestión de residuos de aves de corral en los países en desarrollo características de la gallinaza de las aves de corral. Organización de las Naciones Unidas para la Alimentación y la Agricultura (FAO). revisión del desarrollo avícola, available at http://www.fao.org/docrep/016/al718s/al718s00.pdf (accessed 19 February 2016).

[4] Scherer, N.M., Gibbons, H.L., Stoops, K.B. \& Muller, M., Phosphorus loading of an urban lake by bird droppings. Lake and Reservoir Management, 11(4), pp. 317-327, 1995. http://dx.doi.org/10.1080/07438149509354213 
[5] Leclercq, D.J.J., Howard, C.Q., Hobson, P., Dickson, S., Zander, A.C. \& Burch, M., Controlling cyanobacteria with ultrasound. 43rd International Congress on Noise Control Engineering. Melbourne, Australia. pp. 16-19, November, 2014, ISBN: USB Stick/ Online 978-0-909882-04-4, available at http://www.acoustics.asn.au/conference_proceedings/INTERNOISE2014/papers/p670.pdf (accessed 19 February 2016).

[6] Hedge, E., Investigating the impact of ultrasonic algal control on daphnia in a freshwater ecosystem Dissertation of the BSc degree in Environmental Biology of Lancaster University, 2013, available at http://www.ultrasonicalgaecontrol.co.uk/downloads/E_ Headge_Dissertation.pdf (accessed 19 February 2016). 